\title{
The Impact of Management Information Systems on a South African University's Organisational Processes
}

\author{
*Olabanji. A Oni \\ Gonese G.M \\ Tafadzwa Matiza \\ Department of Business Management, \\ University of Limpopo, Turfloop Campus, Sovenga, South Africa \\ *E-mail: olabanji.oni@ul.ac.za
}

Doi:10.5901/mjss.2014.v5n9p199

\begin{abstract}
This study aimed to determine the impact of management information systems on the organisational performance of a ruralbased university in South Africa, while also exploring the perceived benefits and challenges with regards to the management system currently being utilised by the institution. The study adopted the mixed methods approach to research and employed a combination of probability and non-probability sampling techniques to establish the final sample frame. Descriptive statistics were used to present the data generated by the survey, which utilised questionnaires as its data generation instrument. As a result of this study it was established that there were benefits inherent to the application of management information systems within the institution and that the users of the system were overall satisfied with management information systems as they improved productivity, performance of duties and decision making. However, it also emerged that administrators of the management system were not content with the current system and its utility. The study ultimately recommends that there needs to be increased awareness and training on the utility of the current management information systems, to create a more conducive environment for the implementation of a more modern system that satisfies both academic staff and the system administrators.
\end{abstract}

Keywords: Management information systems, university organisation performance,

\section{Introduction}

Technology plays a pivotal role in the daily operations of most modern business entities, organisations and institutions. Advances in technology and the use of automated equipment has resulted in the faster, improved and more efficient accomplishment of tasks, as well as the simplification data related processes. Hence information systems (IS), have become a vital component of an organization's competitive practices (O'Brien \& Marakas, 2011). Laudon \& Laudon (2009) describe an information system as a set of interrelated components that collect (or retrieve), process, store, and distribute information to support decision-making and control in an organisation. Management information systems (MIS) are information systems which are interconnected mechanisms or apparatuses that are used to gather, process, analyse, accumulate and readily distribute information that is vital for management functions, processes and decision-making. In the context of management, these processes will include planning, organising and controlling computer software that is used to retrieve data as well as store it in a conveniently accessible form.

The organisational structures and cultures of academic institutions are different from that of companies, business organizations and non-profit organizations (Winston, cited in Shoham \& Perry, 2009), with academic institutions, such as universities, being heavily reliant on MIS systems for activities such as student registration, the allocation of resources, library services, online learning and intranet services. Critically, MIS's are an integral part for the administrative management of universities. MIS also include elements of Enterprise Resource Planning (ERP), which is an organisationwide information system that integrates and controls all the business processes in the entire organization (Al-Fawaz, AlSalti \& Eldabi, 2008). MIS's therefore facilitate the administrative function of institution management; however, there is limited empirical data on the value that management information systems bring in the operations of organisations such as academic institutions and universities.

The study sought to evaluate the utilisation of management information systems at a rural-based South African university, as well as assess the impact of MIS on the organisational performance of the institution. The study critically 
addressed the following research questions:

- Of what use are management information systems at the university?

- What are the benefits and drawbacks of using a management information system in the university processes?

- What is the overall impact of MIS on organisational performance?

\section{Review of Related Literature}

Universities around the world are facing the need to adapt to a rapidly changing educational and social landscape, in which technology is both the main cause of change and a tool for dealing with the change (Shoham \& Perry, 2009). Management information systems are basically an integrated user machine system for input and output of data, processing of information and support for operations. The major purpose of an information system is to convert data into information. The system utilises computer hardware and software, manual procedures, models or analysis, planning, control and decision making and database (Ramachandra \& Srinivas, 2012). Information is a crucial resource that is pivotal to the wellbeing and functioning of organisations. Information is defined as data that has been processed or has gone through a process of value addition from its raw state.

Frenzel \& Frenzel (2004), believe management information systems provide a focused view of information flow as it develops during the course of business activities. Information dissemination throughout an organisation is critical for the completion of tasks, activities and for providing means or a basis for formulating decisions. Labour reporting programs, inventory transaction reports, sales analyses, and purchase order systems are some of the many MIS systems (Frenzel \& Frenzel, 2004, Clark, Jones \& Curtis, 2007, Muñiz 2009). MIS's are utilised by universities in numerous processes such as student registration, grading of results, printing facilities, as well as administrative functions such as internal material procurement or checking in of staff members and students at points of entry. Information systems, in turn, can be understood as a group of interrelated components that collect, process, store and disseminate information to support decision making and managerial control (De Oliveira, de Vasconcelos, Queiroz, Queiroz, \&Hékis, 2011).

Shoham \& Perry (2009) articulate that the role of technology in the organizations is complex and significant both as a creator of change and as a tool for dealing with change, sometimes simultaneously. The use of MIS allows for simpler processes, and as de Oliveira et al. (2011) notes, institutions are resorting to technology to enhance and simplify information management. Based on their study on information systems and supply chain management in hotels, Kaya \& Azaltun (2012) found that communication and information sharing among members of the supply chain provides for more effective decisions. By ensuring more effective communication and assimilation of information in an organisation, managers can make more accurate and well informed decisions for their respective departments. According to Ramachandra \& Srinivas (2012), MIS plays a vital role in the management, administration and operations of an organization suggesting that the benefits of using MIS in an organisation include, improving organisational effectiveness, ensuring efficient and effective use of resources, promoting proactive business management, and the development of a learning organisation.

Johnson \& Johnson (2003) in their study of a Sri Lankan open university, suggest that MIS should improve university communication with applicants, students, and alumni, which would also make documentation and database maintenance more efficient. In study on the impact of MIS in the Department of Engineering in a college, Ramachandra \& Srinivas (2012) established the following as reasons for applying MIS in the college:

- The maintaining of attendance all the students of the department

- Calculation of average internal assessment marks of all the students of the department.

- Calculation of percentage of attendance of all the students of the department.

- To sort out the students names who have shortage of attendance.

- The details of the entire faculty in the department handling various subjects for different sections in Undergraduate and Postgraduate courses.

- Calculation of average internal assessment marks of all the students of the department

South Africa has experienced a significant increase in student enrolment in its tertiary institutions since 1994, leading to universities needing to incorporate MIS to accommodate the implications of such growth. A key part of and MIS strategy is to leverage information systems to automate and improve operations, to strengthen management controls, and to enable significant growth (Kesner \& Russell, 2004). The use of management information systems encourages decentralisation, thereby strengthening management controls. The use of MIS also means cost benefits, time-saving and data can easily be accessed and analysed without time consuming manipulation and processing (Pathak, 2011). To this end this study aimed to establish the operational impact of MIS, as well as its perceived benefits and challenges with 
particular reference to a rural-based university in South Africa.

\section{Methodology}

This study made use of a combination of quantitative and qualitative research methods in order to solicit objective data from respondents in a direct manner. Due to the descriptive nature of this study, there was a use of surveys to gather data. It is an appropriate method that can accommodate both qualitative and quantitative techniques for use on this study.

\subsection{Population and Sample}

The population is the comprehensive group or set of subjects from which a study is done. This group may exhibit varying features and characteristics. For the purposes of this study the universal population was approximately 30000 individuals, both students and staff, in four faculties, namely Faculty of Humanities, Faculty of Management and Law, Faculty of Science and Agriculture and lastly the Faculty of Health Sciences. These faculties then branch out into 18 different Schools.

This study utilised a combination of probability and non-probability sampling methods to establish the final sample frame. Purposive sampling was employed to establish the initial population of key informants for the study, these were the administrators of the MIS system at the university, $N=6$. To establish user experience of MIS simple random sampling was employed to select two target faculties to sample. This was achieved by placing all 4 names of the faculties in a hat and picking two randomly. As a result the faculty of Management and Law and the Faculty of Health Sciences were selected, from which a purposive sample of all departmental administrators in these faculties was selected for the study. This is based on the fact that only the chief administrative staff in the faculty has access to full MIS system. As a result a population the $N=10$ MIS administration users was established. Therefore the total population for the study was $N=16$.

\subsection{Data collection and analysis}

This research study made use of both primary and secondary data collection methods. The secondary data was obtained from previous research and literature such as published journals, electronic or online articles, newspaper articles and text books on both management theory and management information systems. The secondary data was used as a guideline for how to conduct the study. The primary data was acquired first-hand through a survey aimed at the University's MIS users.

Survey research, according to Christensen, Johnson \& Turner (2011), is a widely used type of non-experimental research. It is a research method where individuals fill out a questionnaire or are interviewed about their attitudes, activities, opinions, and beliefs. The questionnaire or interview protocol usually is standardised to present each research participant with the same stimulus (i.e., questions, directions). As a result, this study as a descriptive study made use of the questionnaire survey method. The study utilised a cross-sectional approach because it attempted to collect data from subjects within a single, short period of time. The data was collected from subjects only once. The questionnaire was standardised for the 2 respective respondent groups, self-administered, consisting of fully structured questions and made use of ordinal scales. Ordinal scales are appropriate because they allow comparison and establish rank-order between different values of a variable (Bless, Higson-Smith \& Kagee, 2006). In this respect Likert scales were used in the questionnaires. Some questions were open-ended in order to gain more specific data from respondents. The questions that this study sought to address and relate to identifying the uses, advantages and disadvantages of MIS in the case university. Open-ended questions helped get personal opinions concerning MIS from the respondents.

\section{Results}

The response rate is summarised in Table 1, and it shows the response rates for the University Management and the University School Staff. The response rate for University Management was 83\%, whilst the response rate for the School Staff was $90 \%$. The School Staff responded better than the University Management. The response rates for this study are high because it was conducted in a single university, which gave similar conditions to a controlled environment. 
Table 1: Response rate

\begin{tabular}{|l|c|c|c|}
\hline \multicolumn{1}{|c|}{ Respondents } & Number sent & Number Returned & Response Rate \\
\hline University Management & 6 & 5 & $83 \%$ \\
\hline School Staff & 10 & 9 & $90 \%$ \\
\hline Total & 16 & 14 & $87.5 \%$ \\
\hline
\end{tabular}

\subsection{The use of management information systems in the university processes}

\subsubsection{Facilitation of student registration}

The respondents were asked to rate the impact of MIS on some organisational task functions and processes. These questions were to help assess the use of MIS in the university's administration, departments and schools. Both groups of respondents, university management and school staff, were asked to rate the performance of the MIS in facilitating student registration. The results obtained are presented in Table 2 and 3 below:

Table 2: Facilitation of student registration

\begin{tabular}{|l|c|c|c|c|c|c|}
\hline Facilitates student registration & 1 - Very poor & 2 - Poor & 3 - Fair & 4 - Good & 5 - Very good & 6 - Not sure \\
\hline School Staff & 0 & $11 \%$ & $33 \%$ & $33 \%$ & $11 \%$ & $11 \%$ \\
\hline Management & $40 \%$ & 0 & $20 \%$ & $40 \%$ & 0 & 0 \\
\hline
\end{tabular}

Table 3: Facilitation of student registration

\begin{tabular}{|l|c|c|}
\hline \multicolumn{1}{|c|}{ Respondent } & Mean & Standard Deviation \\
\hline University Management & 2.60 & 1.52 \\
\hline School Staff & 3.50 & 0.93 \\
\hline
\end{tabular}

The findings show that the mean response of 2.60 by management, expresses their overall opinion that the MIS is poor at facilitating student registration. The school staff had a mean response of 3.50, indicating that their general perception is that the MIS performs fairly at facilitating student registration. This shows a gap in expectations of the two groups, hinting at probably higher expectations of performance of MIS by the university management than that of the department staff.

\subsubsection{Monitoring attendance of staff and members and students}

Respondents were asked about the MIS performance in monitoring attendance of staff members as well as students.

Table 4: Monitoring of attendance

\begin{tabular}{|l|c|c|c|c|c|c|}
\hline Monitoring attendance of staff members and students & 1 - Very poor & 2 - Poor & 3 - Fair & 4 - Good & 5 - Very good & 6 - Not sure \\
\hline School Staff & $44.45 \%$ & $22.22 \%$ & $11.11 \%$ & $11.11 \%$ & 0 & $11.11 \%$ \\
\hline Management & $20 \%$ & $40 \%$ & $20 \%$ & 0 & 0 & $20 \%$ \\
\hline
\end{tabular}

Table 5: Monitoring of attendance by MIS

\begin{tabular}{|l|c|c|}
\hline \multicolumn{1}{|c|}{ Respondent } & Mean & Standard Deviation \\
\hline University Management & 2.00 & 0.82 \\
\hline School Staff & 1.88 & 1.13 \\
\hline
\end{tabular}

The response "not sure" was excluded from the calculations of the mean and standard deviation (Table 5) to ensure it does not skew the analysis of the Likert scale results. The findings show that management feel the University MIS is poor at monitoring attendance given by their low mean rating of 2.00; whilst the school staff rates the MIS as very poor, given the mean rating of1.88. Judging from the overall responses, we can conclude that the university's MIS does not monitor attendance of neither the staff nor students effectively.

\subsubsection{Facilitating the grading of assessment results}

School staff respondents were asked about their perception of the MIS impact on the grading of assessment results of students. 
Table 6: Facilitating the grading of assessment results

\begin{tabular}{|c|c|c|c|c|c|c|c|}
\hline Facilitating the grading of assessment results & 1 - Very poor & 2 - Poor & 3 - Fair & 4 - Good & 5 - Very good & 6 - Not sure \\
\hline Frequency & 0 & 4 & 3 & 2 & 0 & 0 \\
\hline Percentage & 0 & $44.45 \%$ & $33.33 \%$ & $22.22 \%$ & 0 & 0 \\
\hline
\end{tabular}

The nearly half of the respondents indicated that they think the management information systems in use are poor at facilitating the grading of assessment results. Another $22 \%$ feel that the MIS is fair for this function. This adds up to approximately $67 \%$ of the staff respondents who do not feel that the MIS in place is good at facilitating grading of assessment results.

Table 7: Mean response for facilitation of the grading of assessment results

\begin{tabular}{|c|c|c|}
\hline Respondent: & Mean & Standard Deviation \\
\hline School Staff & 2.78 & 0.83 \\
\hline
\end{tabular}

The low mean response value of 2.78 indicates that school staff generally feels that the MIS in use is poor for purposes such as grading of the results of students. This implies that as MIS users, they are not satisfied with the MIS in place in terms of facilitating grading of students' assessment results. The low standard deviation value of 0.83 indicates that most of the responses were close to poor rating of the MIS.

\subsubsection{Dealing with requisition orders}

School staff respondents were asked about the MIS performance in terms of dealing with requisition orders for stationery and materials. The findings are displayed in Table 8 below.

Table 8: Requisition orders

\begin{tabular}{|c|c|c|c|c|c|c|}
\hline Monitoring resource utilisation & $\mathbf{1}$ - Very poor & $\mathbf{2}$ - Poor & $\mathbf{3}$ - Fair & $\mathbf{4}$ - Good & $\mathbf{5}$ - Very good & $\mathbf{6}$ - Not sure \\
\hline Frequency & 0 & 1 & 1 & 5 & 0 & 2 \\
\hline Percentage & $0 \%$ & $11.11 \%$ & $11.11 \%$ & $55.55 \%$ & $0 \%$ & $22.23 \%$ \\
\hline
\end{tabular}

Table 9: Dealing with requisition orders

\begin{tabular}{|c|c|c|}
\hline Respondents: & Mean & Standard Deviation \\
\hline School staff & 3.57 & 0.79 \\
\hline
\end{tabular}

The response "not sure" was excluded from the calculations of the mean and standard deviation to ensure it does not skew the analysis of the Likert scale results. Judging by the mean response of 3.57, the staff respondents believe the MIS to be good at handling requisition orders for their regular operations and processes. The Standard deviation value of 0.79 is fairly low, implying that majority of the respondents agree with the average rating.

\subsection{The benefits of management information systems in the university processes}

This section seeks to identify the benefits of using management information systems in the university.

\subsubsection{Key benefits of using management information systems in the university}

The respondents were asked to name their own perceived benefits of employing MIS in their daily tasks and operations in the university Table 10.

Table 10: Management perceived benefits of MIS in the University of Limpopo

\begin{tabular}{|l|c|c|}
\hline & Frequency & Percentage \\
\hline Improved access to information & 3 & 30 \\
\hline Accurate information for decision-making & 3 & 30 \\
\hline Time saving & 1 & 10 \\
\hline Data maintenance & 2 & 20 \\
\hline Management control & 1 & 10 \\
\hline Total & 10 & $100 \%$ \\
\hline
\end{tabular}


Management responded as service providers of MIS and indicated (Table 10) their perceived or expected benefits of MIS. The results show that the majority of the management staff believes that MIS improves access to information and accuracy of making informed decisions. This is shown by the $30 \%$ values in the table. Data maintenance is seen as the next key benefit of employing MIS, with a $20 \%$ representation amongst respondents. The other benefits identified are time saving and management control, which were each selected by $10 \%$ of the respondents. The users of the MIS, namely the school staff, also identified benefits to employing MIS in the University of Limpopo. These are outlined in Table 11.

Table 11: School Staff's key benefits of MIS in the University of Limpopo

\begin{tabular}{|l|c|c|}
\hline \multicolumn{1}{|c|}{ Perceived benefit } & Frequency & Percentage \\
\hline Convenience & 5 & 31.25 \\
\hline Avoids human errors & 2 & 12.50 \\
\hline Information spread & 3 & 18.75 \\
\hline Simplified communication & 6 & 37.50 \\
\hline Total & 16 & $100 \%$ \\
\hline
\end{tabular}

The most popular benefit identified by staff members was that of the simplified communication through the use of MIS. It was identified by $38 \%$ of the respondents, which is a significant portion of the respondents as it is identified by almost half. Another popular choice is the increased convenience of carrying out tasks due to MIS implementation. $31 \%$ of the responses indicate that their tasks are made easier because of the use of MIS in the university. 19\% of the responses identify the spreading of information as a key benefit of MIS use, whilst only $13 \%$ of the responses are related to the benefit of reducing human errors. An observation of both empirical findings from the management (providers) and school staff (users) shows that both groups identified access and spreading of information as a key benefit, as well as the element of improved accuracy from the use of MIS in the university.

\subsubsection{Improving data maintenance}

This question sought to find out the extent to which respondents view the impact of the MIS on data maintenance. Both groups were asked to agree or disagree with a statement, and the findings are presented in Table 12.

Table 12: Improving data maintenance

\begin{tabular}{|l|c|c|c|c|c|}
\hline \multicolumn{1}{|c|}{ Statement: } & \multicolumn{3}{|c|}{ The management information system improves data maintenance } \\
\hline Respondents: & Strongly disagree & Disagree & Neutral & Agree & Strongly agree \\
\hline Management & $0 \%$ & $20 \%$ & $0 \%$ & $60 \%$ & $20 \%$ \\
\hline School staff & $0 \%$ & $11.11 \%$ & $11.11 \%$ & $55.55 \%$ & $22.23 \%$ \\
\hline
\end{tabular}

The findings show similar and high percentages of respondents who agree or strongly agree with the statement that MIS improves data maintenance. Given that school staff and management have respective mean responses of 3.80 and 3.89, we can conclude that both respondent groups are leaning towards agreeing that MIS improves data maintenance.

\subsection{The disadvantages of using management information systems in the university processes}

This section seeks to identify the disadvantages of employing management information systems in the university.

\subsubsection{Key disadvantages of using management information systems in the university}

This was an open ended question in which management respondents were asked to identify the key problems or disadvantages of employing MIS in their tasks and daily operations in the university. 
Table 13: Management perceived disadvantages of MIS in the university

\begin{tabular}{|l|c|c|}
\hline \multicolumn{1}{|c|}{ Perceived problem } & Frequency & Percentage \\
\hline CRM wrongly converted into ERP & 1 & 14.25 \\
\hline Inflexibility & 1 & 14.25 \\
\hline People do not understand the MIS & 3 & 43 \\
\hline Difficult to implement at all levels & 1 & 14.25 \\
\hline Lack of MIS training & 1 & 14.25 \\
\hline Total & 7 & $100 \%$ \\
\hline
\end{tabular}

The most common identified problem was that the university personnel do not seem to properly understand the MIS employed. This was reflected in $43 \%$ of the responses and is a significant amount that is almost half of the responses. This makes sense because $14 \%$ believe that there is a lack of MIS training in the university. $14 \%$ of the responses indicate there is difficulty in implementing the MIS in all levels across the university. Another $14 \%$ believe that the MIS in place has an element of inflexibility.

The school staff members were also asked to identify disadvantages of employing MIS in their tasks and operations in the university. The findings are displayed in Table 14 below.

Table 14: School staff's perceived disadvantages of MIS in the university

\begin{tabular}{|l|c|c|}
\hline \multicolumn{1}{|c|}{ Perceived problem } & Frequency & Percentage \\
\hline System not integrated & 2 & 14.3 \\
\hline Users excluded from information & 1 & 7.1 \\
\hline Lack of user training & 4 & 28.6 \\
\hline Users not interested & 1 & 7.1 \\
\hline No problem & 1 & 7.1 \\
\hline MIS not user-friendly & 3 & 21.4 \\
\hline System failure & 2 & 14.3 \\
\hline Total & 14 & $100 \%$ \\
\hline
\end{tabular}

The results indicate 7 disadvantages identified by the school staff. School staff echoes management's sentiment that there is a lack of training for MIS carried out, with a response value of $29 \%$. Another large percentage of responses, $22 \%$, are of the opinion that the MIS is not user-friendly. This disadvantage can be seen as one that further emphasises that there is a need for training on how to use the MIS, especially amongst the users.

Other significant complaints are that the MIS experiences system failure and that the system is not well integrated across the University, each with response values of $14 \%$. The remaining identified disadvantages were that users are excluded from some information; some users are not interested in MIS or its functions and other users do not experience problems with the MIS. It is noteworthy that users complain that the MIS in the university is not integrated well enough and management complains that the MIS is difficult to implement in all levels throughout the university. These two disadvantages could be related, just as both respondent groups indicate a lack of adequate training for users of MIS as a hindrance.

\subsubsection{Implications of MIS failure on staff tasks and operations}

The school staff respondents were asked to indicate the implication on their tasks and operations in the event of any MIS failure. The results are summarised in Table 15 below.

Table 15: The implications of MIS failure

\begin{tabular}{|l|c|c|}
\hline \multicolumn{1}{|c|}{ Implication } & Frequency & Percentage \\
\hline Delay in task completion time & 4 & 44.44 \\
\hline Disrupts tasks and operations & 4 & 44.44 \\
\hline Cannot complete tasks & 1 & 11.12 \\
\hline Total & 9 & 100 \\
\hline
\end{tabular}


From the data acquired, we can see that the majority of the school staff (88\%) either identified the delay in task completion time or disruption of tasks as the main implication of MIS failure. A smaller portion of the staff indicated a resultant inability to complete their tasks. This indicates that only small portions of the school staff members have duties and tasks that are fully reliant on the university MIS, whereas the vast majority can perform other non-MIS related duties.

\subsection{Summary of results}

In this section the empirical findings of the study were presented. The school staff had a higher response rate than the university management. The mean response rate for both groups was $87.5 \%$. The results showed that the management and school staff members have different expectations regarding to the use of MIS in the university processes. It was established that school staff members regard the MIS performance as higher than the university management. The results also identified the different benefits as well as disadvantages of employing MIS in the university from the perspectives of university management and school staff.

As a result of this study, it can be deduced that the University makes use of the management information systems to facilitate student registration. It was also found that the university management are more critical of the management information systems' ability to facilitate registration than the school staff. School staff members are more optimistic and satisfied with the MIS performance than the management staff. The university MIS does not effectively monitor attendance of university personnel or of the students. The MIS is also used to facilitate the grading of student assessment results, however it is considered inadequate by majority of the users, namely the school staff. University management respondents indicated that the MIS falls short for functions such as monitoring resource utilisation, whilst in contrast to this school staff members indicated that the MIS is good at dealing with requisition orders. This is interesting considering the tasks of monitoring resource utilisation and handling requisition orders are fairly related.

\section{Conclusions and Recommendations}

A study conducted on tertiary institutions by de Oliveira et al. (2011) noted that teaching institutions, especially higher education facilities, find themselves in a new era, characterized by expanded teaching horizons. Nowadays there are more and more undergraduate and postgraduate programmes on offer, as well as more lecturers and students and an explosion in knowledge. This means there is a greater demand on MIS to accommodate these larger volumes of people and resultant information. This brings about a need for an improvement in the facilitation of distance learning.

University management staff and school staff at the university in question managed to identify key benefits of employing management information systems from their experiences. Most management staff expressed that the use of MIS improves the accessibility of information across the organisation. These sentiments were also reflected by school staff, who determined that the use of management information systems ensures more effective communication. It can be concluded that MIS improves the accessibility and spreading of information, hence positively impacting organisational performance. School staff also identified that MIS helps to avoid human errors and this is complements management's perception that the use of MIS provides accurate information for decision-making, similarly improving organisational performance. This study further identified benefits were time-saving, improved convenience and greater data maintenance.

University management staff also believes that MIS helps to enhance management control. It can be concluded that the numerous benefits of MIS for school staff members improves their daily operations. In addition, MIS seems more beneficial for the school staff members because MIS management staff expressed they can continue with their work without much use of the MIS. However, management staff stated that the university MIS is inflexible and is difficult to implement at all levels of the University, thus presenting a limitation. Results from both groups convey that people in the University do not fully understand the MIS and that there is a lack of MIS training for the users in the university.

It is recommended that the university management information systems are boosted or upgraded technically with a view to improve reliability and decrease occurrences of system failure. There should also be an improvement in the MIS modules used for student registration, grading of assessment results and possibly provisions made to improve the distribution of academic course content and materials. Measures must be taken to simplify the MIS by means of MIS training initiatives or seminars for the users of the MIS, in order to increase MIS user competence, as well as educate the users on how to use the systems accurately and effectively. In order to effectively realise optimum implementation and use of the MIS, the university management should devise some MIS training programmes or seminars for university staff to properly understand the MIS. It would reduce the amount of complaints about the system being complicated and not user-friendly. If the school staff can improve on their knowledge and understanding of how to use the MIS, then their 
operations are bound to be performed more efficiently and increase their satisfaction of the information systems.

It is also recommended that to improve performance of the MIS, there should be an improvement in the technical reliability of the system in order to reduce the occurrence of system failures or an establishment of backup alternatives in order to counter the disruptive nature of system failure. Nowduri and Srinivas (2011) express that, consequentially, a good management of information systems leads to good decision-making in business just in the same way poor management leads to poor decision making. This means that the onus is for improving the university MIS is on the management staff, by ensuring that the MIS in place is appropriate for the needs of the institution and that they manage it properly. Additionally the concept of reaping what you sow is applicable, in other words lacklustre inputs will only churn out similarly lacklustre output, resulting in poor information for decision-making.

Currently the school staff members are satisfied with the performance of the MIS. This is an anomaly because at the same time the providers of the service are not satisfied. At the same time other acknowledged shortcomings were that the MIS system is not integrated, therefore excluding some information from some users. Users also stated that the MIS system is not user-friendly, or rather complicated to fully understand, as well as being prone to occasional system failures. In the event of system failures, the findings show that there are consequences of delays in task completion time, disrupted tasks and operations, or in some cases uncompleted tasks.

The University must continue to employ MIS in its processes and reap the benefits from the use of MIS. It also improves communication and it would be imperative for the University to always make sure that the MIS in use is contemporary and adequate for the university's needs in order to realise these benefits. But this does not address certain anomalies highlighted by this research.

The fact that the users are relatively more satisfied than the providers; that they all acknowledge benefits of the MIS; but at the same time there are serious problems, indicate that all role players do not realise the level of services that can be provided by the MIS systems of today. Training in the use of present systems is essential as recommended above, but all role players: user staff, students, providers of the MIS services and top management should be educated to understand what can be achieved with a proper integrated system so that the expectations are set at a higher level. Only then will there be enough pressure to improve to the MIS to a level that is achievable and that the University deserves.

\section{References}

Al-Fawaz, K., Al-Salti, Z. \& Eldabi, T. (2008). Critical Success Factors In ERP Implementation: A Review. European and Mediterranean Conference on Information Systems.

Bless, C., Higson-Smith, C. \& Kagee, A. (2006). Fundamentals of Social Research Methods, an African Perspective. Cape Town: Juta\& Co Ltd.

Christensen, L. B, Johnson, R. B. \& Turner, L.A. (2011). Research Methods, Design, and Analysis. Boston: Pearson Education.

Clark, T.D., Jones, M.C., \& Armstrong, C.P. (2007). The Dynamic Structure of Management Support Systems: Theory Development, Research Focus, and Direction. MIS Quarterly, 31(3), pp. 579-615.

de Oliveira, L.A.B, de Vasconcelos, N.V.C., Queiroz, F.C.B.P, Queiroz, J.V. \& Hékis H. R. (2011). Contribution of Integrated Management Systems to University Management: Case Study of the Federal University of Rio Grande Do Norte. Journal of Social Sciences, Vol. 7(3).

Frenzel, C.W. \&Frenzel, J.C. (2004). Management of Information Technology. Course Technology, Canada.

Johnson, R.L. \& Johnson, S. (2003). Potential MIS Contribution to Institutional Strengthening at the Open University of Sri Lanka. OUSL Journal, Vol. 2, pp.26-43.

Kaya, E. \& Azaltun, M. (2012). Role of Information Systems in Supply Chain Management and its Application on Five-Star Hotels in Istanbul. Journal of Hospitality and Tourism Technology, 3(2), pp.138-146.

Kesner, R. M. \& Russell, B. (2004). Enabling Business Processes through Information Management and IT Systems: The Fast Fit and Winter Gear Distributors Case Studies. Journal of Information Systems Education, 20(4), pp.1-6.

Laudon, K.C \& Laudon J.P. (2009). Essentials of Management Information Systems. New Jersey: Pearson Education.

Muñiz, E.J.S. (2009). The Investment in Management Information Systems and Its Effect on the Efficiency in Public Organizations When Putting Into Practice the Alignment Function of Information Technologies Governance. International Journal of Management \& Information Systems, 13 (2), pp21-28.

Nowduri, S. (2011). Management information systems and business decision making: review, analysis, and recommendations. Journal of Management and Marketing Research. [Online] Available: http://www.aabri.com/manuscripts/10736.pdf (Accessed September 28, 2013).

O'Brien, J. A \&Marakas, G. M. (2011). Management Information Systems. New York McGraw-Hill.

Pathak, S.R., (2011). Management Functions and Behaviours: What is the role of Management Information System (MIS) in sustaining efficiency and effectiveness of an organization? [Online] Available:http://ms-01-ignou.blogspot.com/2011/05/what-is-role-of-managementinformation.html (Accessed April 30, 2013).

Ramachandra, C.G, \& Srinivas, T.R. (2012). Management Information System Applied to Mechanical Department of An Engineering College. Journal of Research in Commerce, IT and Management. 2(11), pp.78-86.

Shoham, S. \& Perry, M. (2009). Knowledge Management as a Mechanism for Technological and Organizational Change Management in Israeli Universities. Higher Education Journal, 57(2), pp.227-246. 